\title{
A new equine pericardial stentless valve
}

Xavier M. Mueller, MD

Ludwig K. von Segesser, MD

From the Department of Cardio-vascular Surgery, Centre Hospitalier Universitaire de Sherbrooke, Sherbrooke, Quebec, Canada, ${ }^{\mathrm{a}}$ and the Department of Cardiovascular Surgery, Centre Hospitalier Universitaire Vaudois (CHUV), Lausanne, Switzerland. ${ }^{\mathrm{b}}$

Read at the Eighty-second Annual Meeting of The American Association for Thoracic Surgery, Washington, DC, May 5-8, 2002.

Received for publication May 30, 2002; revisions requested Aug 26, 2002; revisions received Sept 9, 2002; accepted for publication Oct 25, 2002.

Address for reprints: Xavier Mueller, MD, Department of Cardio-vascular Surgery, Centre Hospitalier Universitaire de Sherbrooke, 3001, $12^{\mathrm{e}}$ Avenue Nord, Sherbrooke, Quebec, Canada J1H 5N4 (E-mail: xavier.mueller@usherbrooke.ca).

J Thorac Cardiovasc Surg 2003;125: 1405-11

Copyright (C) 2003 by The American Association for Thoracic Surgery

0022-5223/2003\$30.00+0

doi:10.1016/S0022-5223(02)73242-X
Objective: Small aortic valve replacement remains a challenging hemodynamic problem. A new bioprosthesis (3F Therapeutics, Lake Forest, Calif) was designed to further improve the hemodynamic performance currently achieved with stentless bioprostheses. This valve consists of a tubular structure assembled from 3 equal sections of equine pericardial material, with virtually no foreign material except for a thin polyester ring. Its hemodynamic performance was compared with that of a commercially available stentless prosthesis in a bovine model.

Patients and Methods: Twelve calves $(55 \pm 2.8 \mathrm{~kg}$ ) received a $19-\mathrm{mm} 3 \mathrm{~F}$ valve ( $3 \mathrm{~F}$ group, $\mathrm{n}=6$ ) or a $19-\mathrm{mm}$ stentless control valve (control group, $\mathrm{n}=6$ ). The animals were fully equipped for hemodynamic monitoring and transvalvular gradient measurements. After implantation, dopamine was infused in increasing doses, and the hemodynamic values were recorded at each step of $100-\mu \mathrm{g} / \mathrm{min}$ increase. Linear regression analysis was applied for group comparison of each variable.

Results: The mean transvalvular gradient at $4.5 \mathrm{~L} / \mathrm{min}$ was $3.48 \pm 0.14 \mathrm{~mm} \mathrm{Hg}$ (95\% confidence interval) in the $3 \mathrm{~F}$ group and $5.72 \pm 0.28 \mathrm{~mm} \mathrm{Hg}$ in the control group $(P<.0001)$ and at $6.5 \mathrm{~L} / \mathrm{min}, 7.4 \pm 1.55 \mathrm{~mm} \mathrm{Hg}$, and $11.13 \pm 0.18 \mathrm{~mm} \mathrm{Hg}$, respectively $(P<.0001)$. The effective orifice area at $4.5 \mathrm{~L} / \mathrm{min}$ was $2.4 \pm 0.03 \mathrm{~cm}^{2}$ in the $3 \mathrm{~F}$ group and $1.86 \pm 0.02 \mathrm{~cm}^{2}$ in the control group $(P<.0001)$ and at 6.5 L/min, $2.41 \pm 0.04 \mathrm{~cm}^{2}$, and $1.96 \pm 0.02 \mathrm{~cm}^{2}$, respectively $(P<.0001)$.

Conclusions: This new bioprosthesis without a stent and without a supporting wall that has its commissures fixed directly to the aorta outperforms in vivo standard stentless prostheses in the immediate postimplant period.

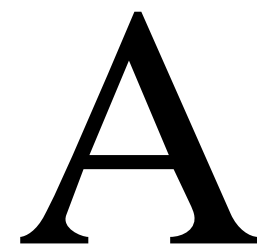

lthough stented bioprostheses avoid the need for anticoagulation, valve stents have 2 main drawbacks. First, stents have been shown to increase stress on the biologic cusp tissue in fatigue-testing models. ${ }^{1}$ This feature has been involved as the source of leaflet calcification, with subsequent limited valve durability. Second, the obstructive nature of rigid stents leads to a nonphysiologic flow pattern and residual gradient, which would inhibit complete resolution of left ventricular hypertrophy and lead to lower long-term survival. ${ }^{2}$

Stentless aortic xenograft valves offer the potential to overcome the problems associated with stented valves and to mimic the hemodynamic performance of homografts. ${ }^{3}$ Despite excellent initial results after its clinical introduction, ${ }^{4,5}$ premature structural deterioration because of poor preservation methods hampered its further application. The introduction of glutaraldehyde by Carpentier and associates $^{6}$ in 1968, with the subsequent widespread use of stented bioprostheses in the early 1980s, renewed the interest in stentless xenograft valves. David and colleagues $^{7}$ began to implant stentless porcine aortic valves in sheep in 1988, with encouraging hemodynamic results. The 1990s have witnessed the introduction of innovative stentless aortic valves, among which the United States Food and Drug Administration approved the Toronto SPV valve (St Jude Medical, Inc, St Paul, Minn) and the Freestyle valve (Medtronic, Inc, Minneapolis, Minn). 


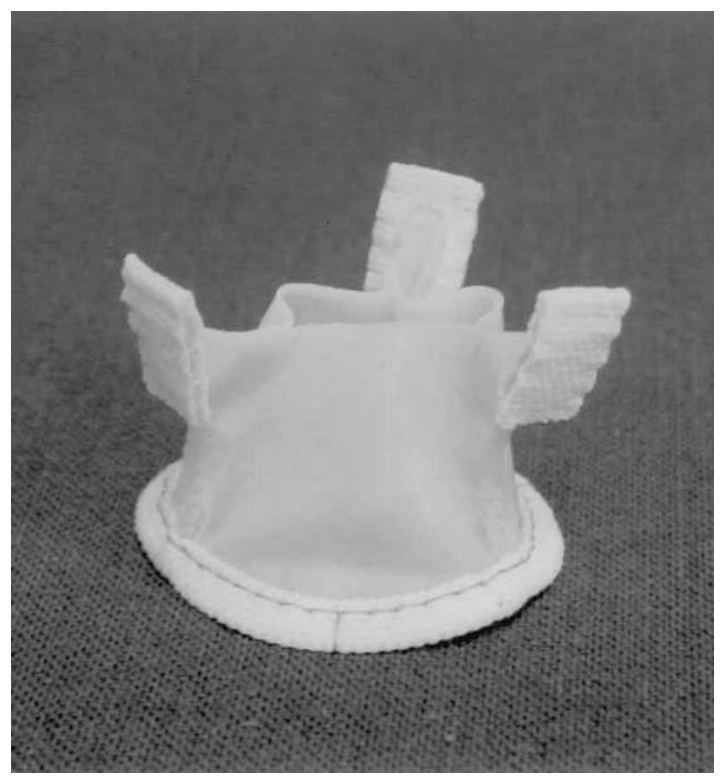

Figure 1. 3F aortic pericardial bioprosthesis.

Nevertheless, any aortic valve substitute, even the stentless valve, has its inherent obstructive feature. In both the Toronto SPV and Freestyle valves, the leaflets are supported by a Dacron cloth, as well as by the aortic wall of the xenograft. This support apparatus represents additional material within the recipient root. A new bioprosthesis (3F Therapeutics, Lake Forest, Calif) was designed to further diminish these obstructive features. This valve consists of a tubular structure assembled from 3 equal sections of equine pericardial material with virtually no foreign material except for a thin polyester ring. Because residual gradient is a concern, especially in patients with small aortic roots, this experimental study was designed to compare the hemodynamic performance of the $19-\mathrm{mm} 3 \mathrm{~F}$ valve with that of the Toronto SPV valve of corresponding size in a calf model.

\section{Material and Methods \\ Study Design}

The protocol described herein was reviewed and approved by the Committee on Animal Care, Office Vétérinaire Cantonal, Lausanne, Switzerland. All animals received care in compliance with the "Principles of Laboratory Animal Care" formulated by the National Society for Medical Research, and the "Guide for the Care and Use of Laboratory Animals" prepared by the Institute of Laboratory Animal Resources, National Research Council, and published by the National Academy Press, revised 1996.

\section{Valve Design}

The $3 \mathrm{~F}$ valve is a low-pressure glutaraldehyde-fixed pericardial bioprosthesis that consists of a tubular structure assembled from 3 equal sections of equine pericardial material (Figure 1). The 3 leaflets have been assembled with locking sutures. Three tabs have been placed at the outflow, simulating commissures that allow fixation in the vicinity of the sinotubular junction. These tabs are reinforced with equal sections of polyester material that also will serve to promote ingrowth of the tab into the aortic wall. Leaflets and tabs are one integral structure. At the inflow area of the tubular structure, a slightly scalloped polyester ring has been incorporated to allow easy suturing of the bioprosthesis to the bottom of the aortic sinus, thus securing it and minimizing the potential for perivalvular leakage. It is expected that this ring will help the promotion of ingrowth of fibrous material to anchor the valve firmly to the root of the aorta.

The tubular structure design was derived from the primal tubular structure of human heart valves found during their development in utero. When the blood flow through the heart is established, this tubular structure adopts the form found when fully developed. That is to say that "Form Follows Function" (3F). Figure 2 illustrates this concept.

\section{Animal Preparation}

This study was conducted in 12 calves with a mean body weight of $55 \pm 2.8 \mathrm{~kg}$ (SD). This weight range was chosen because it corresponds to an aortic annulus size of $19 \mathrm{~mm}$. The animals were equipped, after achievement of general anesthesia, with a SwanGanz catheter (Edwards Lifesciences, Irvine, Calif) and a femoral arterial catheter for hemodynamic monitoring. The Swan-Ganz catheter was inserted through the right jugular vein into the pulmonary artery to measure pressures of the right-sided heart chambers with continuous cardiac output monitoring (Vigilance Monitor; Baxter, Irvine, Calif). Three electrocardiographic leads were installed. A median sternotomy was performed. The pericardium was opened and reflected to form a cradle for suspending the heart. Two 8F high-fidelity micromanometer-tipped catheters (Millar Instruments, Inc, Houston, Tex) were inserted into the left ventricle through the apex of the heart and into the ascending aorta through the left internal thoracic artery, respectively. Simultaneous recording of the left ventricular pressure and the ascending aortic pressure was used to measure transvalvular gradient. Heparin (F. Hoffmann-La Roche \& Co, Basle, Switzerland), 300 IU/kg body weight, was given systemically, and the activated clotting time was kept at greater than 400 seconds throughout the experiment.

Because of the short length of the ascending aorta, both the right carotid artery and the aortic arch were cannulated. For the venous return, a double-stage cannula was introduced into the right atrium. A standard cardiopulmonary bypass (CPB) circuit was connected. Whole-body perfusion was then instituted, with the blood flow rate maintained by a roller pump at 60 to $80 \mathrm{~mL} \cdot \mathrm{kg}^{-1}$ - $\min ^{-1}$. Body temperature was lowered to $28^{\circ} \mathrm{C}$. After the brachiocephalic trunk and the ascending arch had been crossclamped with a single clamp, $1 \mathrm{~L}$ of cold crystalloid solution was injected through a cardioplegia needle at the base of the aorta. The distal ascending aorta was transected to expose the aortic valve and to allow maximal length of the aortic root for proper implantation of the valve. The transection provides better exposure than when the aorta is not completely transected, and it preserves the normal anatomic structure of the root. The native aortic cusps were then carefully excised.

The 12 animals were randomly assigned to either a $3 \mathrm{~F}$ valve (3F group) or a Toronto SPV valve (control group). Before implantation, the aortic annulus size was assessed with a 19-mm 
Hegar dilator. When a 3F valve was inserted, its polyester ring was secured to the annulus with 2-0 Ti-Cron (United States Surgical Corp, Norwalk, Conn) interrupted sutures. Then each tab was fixed to the aortic wall with a transmural 4-0 Prolene (Ethicon, Inc, Somerville, NJ) U stitch.

When a Toronto SPV valve was used, its annulus was secured in a similar fashion. The valve was oriented such that the largest opening faced the left ostium. After tying the proximal suture line, the commissural posts were held in place with stay sutures of 4-0 Prolene to achieve proper orientation. Then the distal suture line was performed with a running 4-0 Prolene suture.

After valve implantation, the aorta was partially closed with a running 4-0 Prolene suture. Once the deairing maneuver was performed, the aortotomy was sealed and the crossclamp was removed. After rewarming, the heart was defibrillated if necessary. When normal sinus rhythm was established, the animal was carefully weaned from CPB with a dopamine support of $200 \mu \mathrm{g} / \mathrm{min}$, and volume was adjusted as needed.

\section{Hemodynamic Recording}

After weaning from CPB, a period of 20 minutes of stabilization was allowed before recording the cardiac output, the mean transvalvular gradient, and the maximal transvalvular gradient. Data were recorded digitally online with a sampling rate of $250 \mathrm{~Hz}$ per channel (Transceiver unit TRx 001; Sonometrics, London, Ontario, Canada). Mathematic analysis of the data was performed offline with a software package for cardiovascular analysis (Sonosoft version 3.1.3., Sonometrics). The hemodynamic data were obtained by measuring 5 consecutive beats twice at 1 -minute intervals. Then the dose of dopamine was increased at 20-minute intervals by using $100 \mu \mathrm{g} / \mathrm{min}$. At the end of each period, the hemodynamic data were recorded. The procedure was stopped when the heart rate exceeded 120 beats/min.

\section{Calculations}

Valve orifice area (VOA) in square centimeters was calculated by the formula of Gorlin and Gorlin ${ }^{8}$ :

$$
\mathrm{VOA}=\mathrm{CO} / 44.3(\mathrm{SEP})(\mathrm{HR}) \vee \mathrm{MPG}
$$

where $\mathrm{CO}$ is the cardiac output (in liters per minute), SEP is the systolic ejection period (in milliseconds), HR is the heart rate (in beats per minute), and MPG is the mean pressure gradient (in milliliters of mercury).

The valve resistance (VR; dyne $\cdot \mathrm{cm} \cdot \mathrm{s}^{-5}$ ) was calculated according to the following formula ${ }^{9}$ :

$$
\mathrm{VR}=1.33(\mathrm{MPG})(\mathrm{HR})(\mathrm{SEP}) / \mathrm{CO}
$$

\section{Statistics}

Values are given as means \pm SD. Correlations between hemodynamic parameters (mean transvalvular gradient, maximal transvalvular gradient, valve orifice area, and valve resistance) and cardiac output were performed with linear regression analysis, according to the least-squares method. Then each hemodynamic parameter, as determined by means of regression analysis, was further examined with the unpaired Student $t$ test between the 2 valve groups.

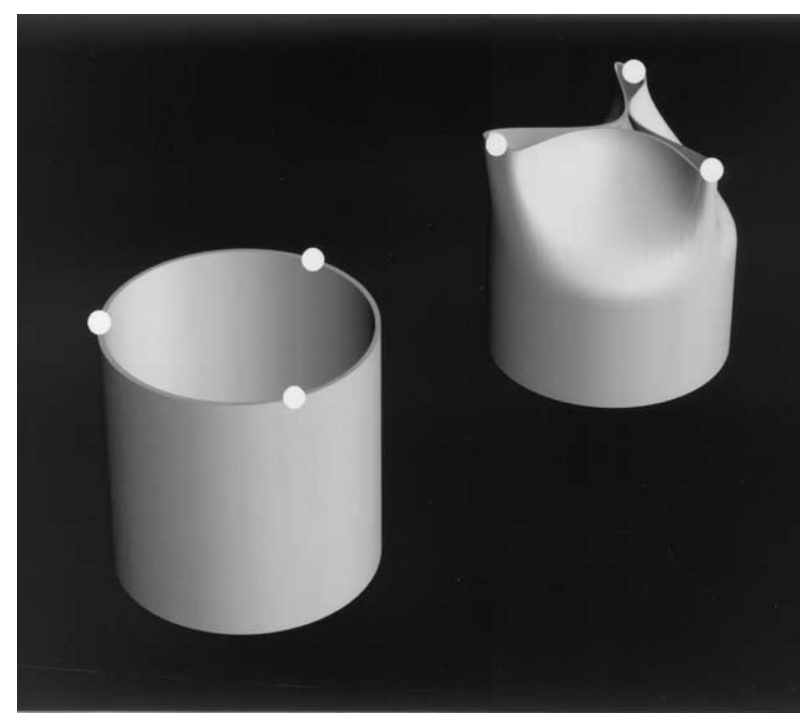

Figure 2. A, Primal tubular structure of human heart valve during development in utero. $B$, The white dots indicate the points of fixation of the tubular structure (ie, the commissural areas). When fluid flows through this tubular structure, the points of fixation will automatically determine the form of the valve.

\section{Results}

The 3F aortic valve could be implanted in all the animals, with successful weaning from CPB and complete hemodynamic measurements obtained. Sinus rhythm was maintained during the complete set of measurements. Four steps of measurements could be performed in each animal, except for one animal in the standard group, in which 5 steps could be performed. Therefore, for each parameter, 240 measurements were available in the $3 \mathrm{~F}$ group and 250 measurements in the standard group.

The mean heart rate was $89.7 \pm 11.9$ beats/min during the first series of measurements and $116.4 \pm 3$ beats/min during the last series. Aortic crossclamp time was $74 \pm 7$ minutes for the $3 \mathrm{~F}$ group and $92 \pm 5$ minutes for the control group $(P<.0001)$.

Linear regression analysis of the mean transvalvular gradient according to the cardiac output is shown on Figure 3. The difference between both groups is statistically significant $(P<.0001)$, with gradients of $3.48 \pm 0.14 \mathrm{~mm} \mathrm{Hg}$ (95\% confidence interval [CI]) for the $3 \mathrm{~F}$ group versus 5.72 $\pm 0.28 \mathrm{~mm} \mathrm{Hg}$ for the standard group at $4.5 \mathrm{~L} / \mathrm{min}$ and gradients of $7.4 \pm 1.55 \mathrm{~mm} \mathrm{Hg}$ versus $11.13 \pm 0.18 \mathrm{~mm} \mathrm{Hg}$ at $6.5 \mathrm{~L} / \mathrm{min}$, respectively.

Figure 4 shows the linear regression analysis of the maximal transvalvular gradient according to the cardiac output. The difference between both groups was statistically significant $(P<.0001)$, with gradients of $30.75 \pm 0.55 \mathrm{~mm}$ $\mathrm{Hg}(95 \% \mathrm{CI})$ for the $3 \mathrm{~F}$ group versus $43.88 \pm 0.9 \mathrm{~mm} \mathrm{Hg}$ 


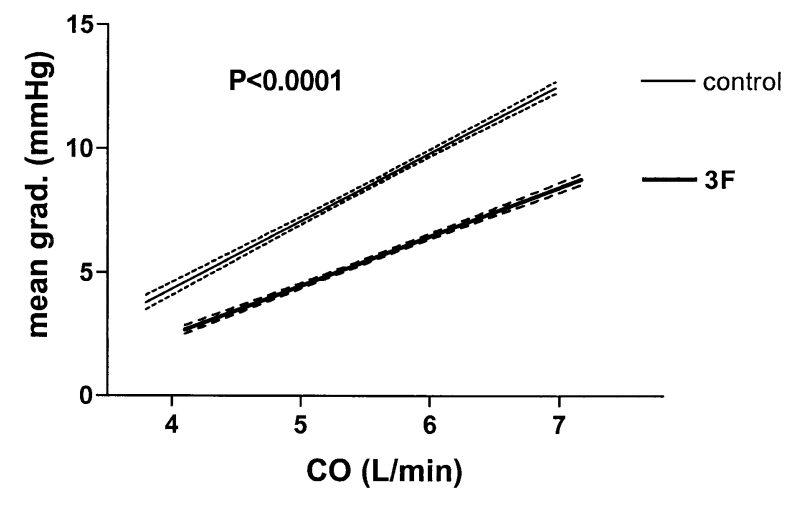

Figure 3. Mean transvalvular gradient: regression analysis according to the cardiac output (CO). Dotted lines, $95 \% \mathrm{Cl}$.

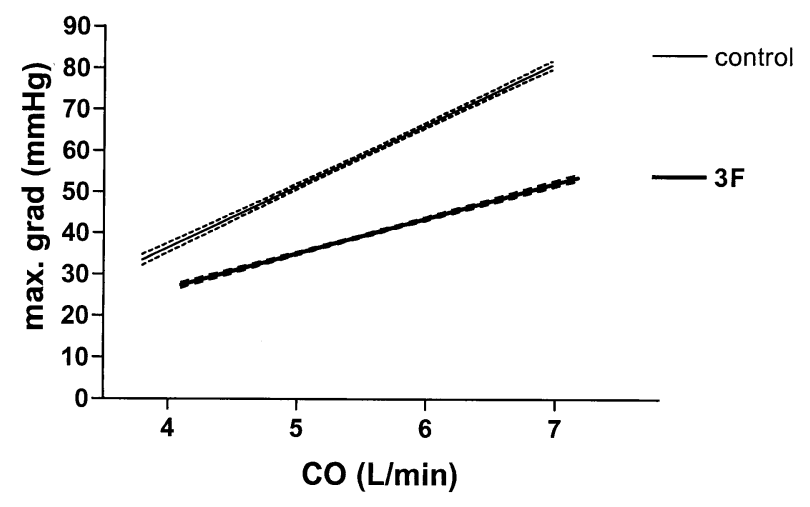

Figure 4. Maximal transvalvular gradient: regression analysis according to the cardiac output (CO). Dotted lines, 95\% Cl.

for the standard group at $4.5 \mathrm{~L} / \mathrm{min}$ and gradients of 47.73 $\pm 0.59 \mathrm{~mm} \mathrm{Hg}$ versus $73.5 \pm 0.8 \mathrm{~mm} \mathrm{Hg}$ at $6.5 \mathrm{~L} / \mathrm{min}$, respectively.

Linear regression analysis of the valve orifice area according to the cardiac output is shown in Figure 5. The difference between both groups was statistically significant $(P<.0001)$, with values of $2.4 \pm 0.03 \mathrm{~cm}^{2}(95 \% \mathrm{CI})$ for the $3 \mathrm{~F}$ group versus $1.86 \pm 0.02 \mathrm{~cm}^{2}$ for the standard group at $4.5 \mathrm{~L} / \mathrm{min}$ and values of $2.41 \pm 0.04 \mathrm{~cm}^{2}$ versus $1.96 \pm 0.02$ $\mathrm{cm}^{2}$ at $6.5 \mathrm{~L} / \mathrm{min}$, respectively.

Figure 6 describes the linear regression analysis of the valve resistance according to the cardiac output. The difference between both groups was statistically significant $(P<$ $.0001)$, with values of $23.76 \pm 0.76 \mathrm{dyne} \cdot \mathrm{cm} \cdot \mathrm{s}^{-5}(95 \%$ CI) for the $3 \mathrm{~F}$ group versus $39.05 \pm 0.99 \mathrm{dyne} \cdot \mathrm{cm} \cdot \mathrm{s}^{-5}$ for the standard group at $4.5 \mathrm{~L} / \mathrm{min}$ and values of $34.15 \pm 0.81$ dyne $\cdot \mathrm{cm} \cdot \mathrm{s}^{-5}$ versus $51.12 \pm 0.87$ dyne $\cdot \mathrm{cm} \cdot \mathrm{s}^{-5}$, respectively, at $6.5 \mathrm{~L} / \mathrm{min}$.

Detailed figures of the regression analysis are shown in Table 1.

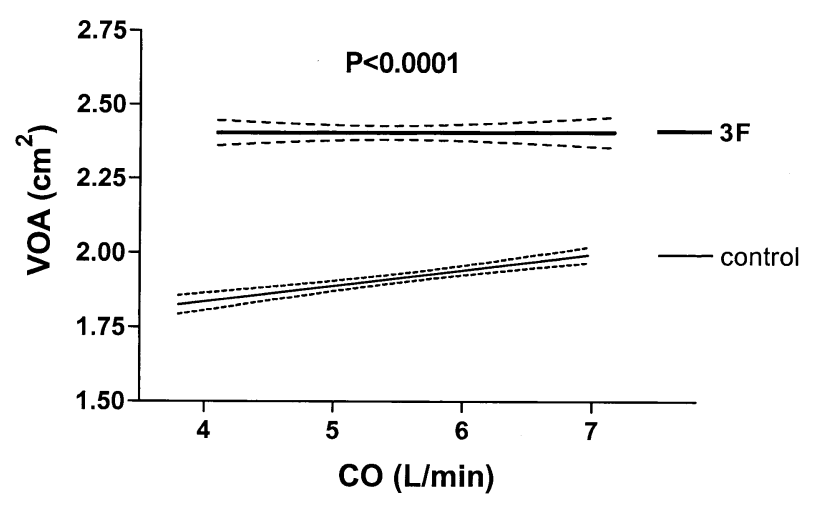

Figure 5. Valve orifice area (VOA): regression analysis according to the cardiac output (CO). Dotted lines, $95 \% \mathrm{Cl}$.

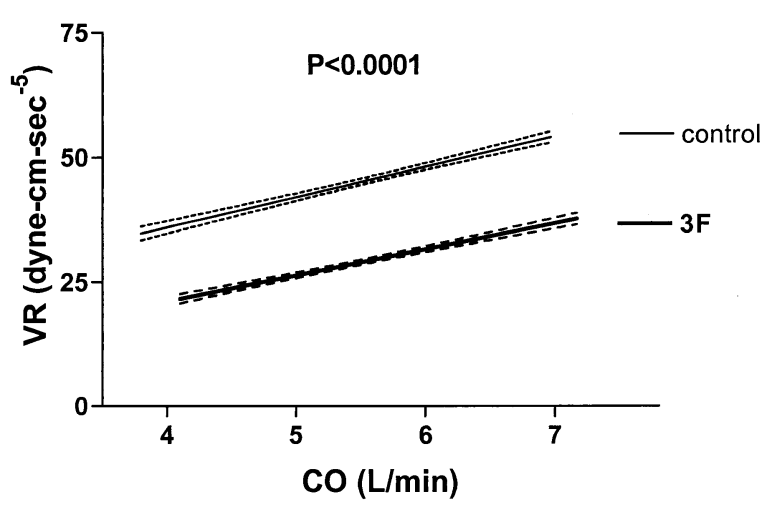

Figure 6. Valve resistance (VR): regression analysis according to the cardiac output (CO). Dotted lines, $95 \% \mathrm{Cl}$.

\section{Discussion}

This in vivo hemodynamic study comparing the $19-\mathrm{mm} 3 \mathrm{~F}$ valve with the 19-mm Toronto SPV valve shows a clear advantage for the $3 \mathrm{~F}$ valve both in term of implantation time and hemodynamic profile. All the hemodynamic parameters studied were improved over the whole range of cardiac output tested. As expected, transvalvular gradients and valve resistance increased with cardiac output in both groups. Interestingly, valve orifice area increased with cardiac output in the Toronto SPV group, whereas it remained stable in the $3 \mathrm{~F}$ group, with clearly superior values even at the higher end of the cardiac output spectrum.

The principle of the $3 \mathrm{~F}$ valve reverses the usual concept of imitating the final form of a defined structure. On the contrary, the $3 \mathrm{~F}$ design is derived from the primal tubular structure of human heart valves found during their original development. The 3 points of fixation of this tubular structure will determine the subsequent form of the valve once blood flow is established (ie, once its function is acquired). This concept allows for a dramatic simplification of the 
TABLE 1

\begin{tabular}{|c|c|c|c|c|c|c|c|c|}
\hline & $\begin{array}{c}\text { Mean } \\
\text { gradient } \\
\text { 3F }\end{array}$ & Control & $\begin{array}{c}\text { Maximum } \\
\text { gradient } \\
\text { 3F } \\
\end{array}$ & Control & $\begin{array}{c}\text { Valve orifice } \\
\text { area } \\
\text { 3F }\end{array}$ & Control & $\begin{array}{c}\text { Valve } \\
\text { resistance } \\
3 \mathrm{~F} \\
\end{array}$ & Control \\
\hline $\begin{array}{l}\text { Slope } \\
95 \% \mathrm{Cl}\end{array}$ & $\begin{array}{l}1.97 \pm 0.05 \\
1.86 \text { to } 2.09\end{array}$ & $\begin{array}{l}2.73 \pm 0.07 \\
2.58 \text { to } 2.87\end{array}$ & $\begin{array}{l}8.55 \pm 0.22 \\
8.12 \text { to } 8.99\end{array}$ & $\begin{array}{l}14.93 \pm 0.32 \\
14.3 \text { to } 15.56\end{array}$ & $\begin{array}{c}0.001 \pm 0.01 \\
-0.02 \text { to } \\
0.02\end{array}$ & $\begin{array}{l}0.05 \pm 0.01 \\
0.03 \text { to } 0.06\end{array}$ & $\begin{array}{l}5.23 \pm 0.3 \\
4.64 \text { to } 5.8\end{array}$ & $\begin{array}{l}6.08 \pm 0.34 \\
5.4 \text { to } 6.76\end{array}$ \\
\hline $\begin{array}{l}\text { Deviation from } \\
\quad 0(P)\end{array}$ & $<.0001$ & $<.0001$ & $<.0001$ & $<.0001$ & .93 & $<.0001$ & $<.0001$ & $<.0001$ \\
\hline $\begin{array}{l}Y \text { intercept } \\
95 \% \mathrm{Cl} \\
R^{2}\end{array}$ & $\begin{array}{c}-5.43 \pm 0.31 \\
-6.05 \text { to }-4.8 \\
0.83\end{array}$ & $\begin{array}{c}-6.57 \pm 0.41 \\
-7.39 \text { to }-5.76 \\
0.85\end{array}$ & $\begin{array}{c}-7.77 \pm 1.22 \\
-10.17 \text { to }-5.38 \\
0.86\end{array}$ & $\begin{array}{c}-23.35 \pm 1.82 \\
-26.92 \text { to }-19.78 \\
0.89\end{array}$ & $\begin{array}{c}2.39 \pm 0.07 \\
2.25 \text { to } 2.54 \\
<0.0001\end{array}$ & $\begin{array}{c}1.62 \pm 0.04 \\
1.53 \text { to } 1.71 \\
0.14\end{array}$ & $\begin{array}{c}0.19 \pm 1.66 \\
-3.06 \text { to } 3.46 \\
0.55\end{array}$ & $\begin{array}{c}11.65 \pm 1.98 \\
7.77 \text { to } 15.53 \\
0.54\end{array}$ \\
\hline
\end{tabular}

prosthetic structure. When compared with the Toronto SPV valve and the Freestyle valve, 3 features have been fundamentally modified: the absence of a supporting xenograft aortic wall, the reduction of synthetic cloth, and the absence of a muscle bar.

First, there is no supporting wall. This might reduce transprosthetic gradients in 2 ways. On the one hand, the xenograft aortic wall itself is an obstructive element once implanted within the native aortic root. On the other hand, analysis of hemodynamics and left ventricular mass regression after implantation of the Toronto SPV valve, ${ }^{10-12}$ as well as the Freestyle valve, ${ }^{13-15}$ have shown repeatedly a significant decrease in transvalvular gradient over the first year after implantation. Although ventricular remodeling has been involved as the major contributor to this decrease beyond the first 3 to 6 postoperative months, absorption of the hematoma in the potential space between the porcine and the native aortic walls appears more likely to be the predominant mechanism in the early postoperative period. The absence of any supporting structure offers to the $3 \mathrm{~F}$ valve the potential for optimal gradient as soon as the implantation time. This hypothesis is supported by the analysis of gradient profile over the time of the Freestyle valve implanted as a root replacement. ${ }^{16}$ In contrast to the subcoronary implant technique and the inclusion technique, early and late gradients were both low and did not change with time.

Second, the absence of foreign material except for a thin polyester ring contrasts with the heavy external Dacron support found especially in the Toronto SPV valve. This avoids any unnecessary increase in thickness of the xenograft. Therefore, artificially induced stiffness or stress on the tissue can be reduced. In keeping with this concept, the reduction of synthetic supporting structure allows for the reduction of suture lines.

Third, the pericardial structure of the $3 \mathrm{~F}$ valve avoids the presence of the unfavorable muscle bar characteristic of the base of the porcine right coronary leaflet, therefore maximizing the valve orifice area. Moreover, coronary ostial position relative to the annulus might further exaggerate the problem of the muscle bar. Westaby and coworkers ${ }^{13}$ have described the potential pitfall of Freestyle valve linked with the Dacron structure, particularly over the muscle bar area, thus generating increased transvalvular gradients.

One of the primary aims of eliminating stents from bioprosthetic valves was to use the sinus of Valsalva of the native or xenograft aortic root as a functional stent. This would allow the leaflets to open more fully as commissures are pulled apart during systole. Despite the absence of rigid stents, all currently available stentless valves have some xenograft or synthetic supporting structure, which might be viewed as soft stents. The $3 \mathrm{~F}$ valve explores the stentless concept further by eliminating supporting components of any kind.

A substantial advantage of $3 \mathrm{~F}$ valve implantation lies in its shorter time of implantation. Instead of 2 suture lines, the technique involves only one inflow suture line and 3 commissural stitches, allowing for reduced crossclamp time. Moreover, the pliability of the valve facilitates its manipulation, which might be particularly relevant in a small aortic root. The stability of the $3 \mathrm{~F}$ valve orifice area at all cardiac output values tested might be related to its simplified and pliable structure, contrasting with the greater inertia of the Toronto SPV valve, especially at low flow rates.

Several features of the study deserve comment. A calf model has several advantages over other animal models for acute hemodynamic study of aortic prosthetic valves. A pig model is limited by post-CPB complications, sheep have a narrow and fragile aortic root, and goats have limited availability.

An in vivo rather than in vitro study was performed because in vitro values have been shown to be unable to predict the behavior of stentless prostheses in vivo. ${ }^{17}$ Valve orifice areas were found to be lower in vivo because stentless valves somewhat collapse when inserted in vivo, whereas in vitro the prostheses are fully expanded and behave more like stented prostheses.

The 19-mm size was chosen for 2 reasons. On the one hand, the performance of a valve is better challenged with small-sized versions. On the other hand, a small aortic root 
is an increasing problem with the aged population. In a multicenter study, Hvass and associates ${ }^{18}$ found $171(30 \%)$ of 561 patients with a small aortic root as defined by a 19to 21-mm aortic annulus. In patients older than 80 years of age, the percentage reached $40 \%$.

A protocol testing hemodynamics over a wide range of cardiac output allows a better evaluation of valve performance when compared with most clinical studies performing echocardiographic evaluation at rest only. Moreover, most of these echocardiographic studies do not mention the cardiac output value at the time of the examination. ${ }^{10,11,13-15}$ This lack makes any comparison difficult because mean transvalvular gradient, maximal transvalvular gradient, and valve orifice area have all been demonstrated to be flow dependent. ${ }^{19-21}$

A comparative study was designed because absolute values found in the experimental setting cannot be extrapolated directly to human subjects, mainly because of anatomic differences. For instance, in this study maximal transvalvular gradients have been found to be disproportionately high in comparison with mean transvalvular gradients. This is likely because of the particularly thickened aortic wall of the calf, which offers a low compliant outflow chamber to transvalvular blood flow.

As for limitations, this acute experimental model does not evaluate the long-term outcome of prosthetic valves, namely degeneration and durability. The theoretical reduction in leaflet stress leading to improved durability remains a challenging issue that needs further evaluation. Second, the sinotubular junction size in human subjects might be larger than that of the annulus. In the Toronto valve experience, David ${ }^{22}$ recommended that the prosthesis should be sized at the sinotubular junction. This usually leads to an oversizing of the prosthesis when referred to the annulus. The problem of $3 \mathrm{~F}$ valve sizing deserves further evaluation. Finally, candidates for aortic valve replacement might exhibit a dilative tendency at the level of the sinotubular junction, which might develop over time. This issue has been shown to have relevant consequences in terms of late prosthetic regurgitation. ${ }^{23}$ Whether the recommendation of banding the sinotubular junction at the time of Toronto SPV valve implantation should be applied to the $3 \mathrm{~F}$ valve needs to be evaluated.

We thank Philippe Frascarolo, PhD, for his help in the statistical evaluation of this article.

\section{References}

1. Vesey I, Boughner S, Tong T. Tissue buckling as a mechanism of bioprosthetic valve failure. Ann Thorac Surg. 1988;48:302-8.

2. Christakis GT, Joyner CD, Morgan CD, et al. Left ventricular mass regression early after aortic valve replacement. Ann Thorac Surg. 1996;62:1084-9.

3. Ross DN. Homograft replacement of the aortic valve. Lancet. 1962; $2: 487-8$.
4. Binet JP, Duran CG, Carpentier A, Langlois J. Heterologous aortic valve transplantation. Lancet. 1965;2:1275.

5. O'Brien MF, Neilson GH, Galea EG, Molph R, Power W, Lomas C. Heterograft valves: an analysis of clinical results of valve replacement. Circulation. 1970;16(Suppl):II16-9.

6. Carpentier A, Lemaigre G, Robert L, Carpentier S, Dubost C. Biological factors affecting long-term results of valvular heterografts. J Thorac Cardiovasc Surg. 1969;58:467-83.

7. David TE, Ropchan GC, Butany GW. Aortic valve replacement with stentless porcine bioprosthesis. J Card Surg. 1988;3:501-5.

8. Gorlin R, Gorlin SG. Hydraulic formula for calculation of the area of the stenotic mitral, other cardiac valves and central circulatory shunts. Am Heart J. 1951;41:1-29.

9. Cannon SR, Zile MR, Crawford M, Carabello BA. Aortic valve resistance as an adjunct to the Gorlin formula in assessing the severity of aortic stenosis in symptomatic patients. J Am Coll Cardiol. 1992; 20:1517-23.

10. Del Rizzo DF, Goldman BS, Christakis GT, David TE. Hemodynamic benefits of the Toronto stentless valve. J Thorac Cardiovasc Surg. 1996;112:1431-46.

11. David TE, Feindel CM, Scully HE, Bos J, Rakowski H. Aortic valve replacement with stentless porcine aortic valves: a ten-year experience. J Heart Valve Dis. 1998;7:250-4.

12. Bach DS, David T, Yacoub M, et al. Hemodynamics and left ventricular mass regression following implantation of the Toronto SPV stentless porcine valve. Am J Cardiol. 1998;82:124-9.

13. Westaby S, Jin XY, Katsumata T, Arifi A, Braidley P. Valve replacement with a stentless bioprosthesis: versatility of the porcine aortic root. J Thorac Cardiovasc Surg. 1998;116:477-84.

14. Cartier PC, Dumesnil JG, Métras J, et al. Clinical and hemodynamic performance of the Freestyle aortic root bioprosthesis. Ann Thorac Surg. 1999;67:345-51.

15. Kappetein AP, Braun J, Baur LH, et al. Outcome and follow-up of aortic valve replacement with the Freestyle stentless bioprosthesis. Ann Thorac Surg. 2001;71:601-8.

16. Kon ND, Cordell AR, Adair SM, Dobins JE, Kitzman DW. Aortic root replacement with the Freestyle stentless porcine aortic root bioprosthesis. Ann Thorac Surg. 1999;67:1609-16.

17. Dumesnil JG, LeBlanc MH, Cartier P, et al. Hemodynamic features of the Freestyle aortic bioprosthesis compared with stented bioprosthesis. Ann Thorac Surg. 1998;66:S130-3.

18. Hvass U, Palatianos GM, Frassani R, Puricelli C, O’Brien M. Multicenter study of stentless valve replacement in small aortic root. $J$ Thorac Cardiovasc Surg. 1999;117:267-72.

19. Takakura H, Sasaki T, Hashimoto K, et al. Hemodynamic evaluation of 19-mm Carpentier-Edwards pericardial bioprosthesis in aortic position. Ann Thorac Surg. 2001;71:609-13.

20. Yoganathan AP, Woo YR, Sung HW, Williams FP, Franch RH, Jones $M$. In vitro hemodynamic characteristics of tissue bioprosthesis in the aortic position. J Thorac Cardiovasc Surg. 1986;92:198-209.

21. Cosgrove DM, Lytle BW, Williams GW. Hemodynamic performance of the Carpentier-Edwards pericardial valve in the aortic position in vivo. Circulation. 1985;72(Suppl):II146-52.

22. David TE. Surgery of the aortic valve. Curr Probl Surg. 1999;36:421504.

23. David TE, Ivanov J, Eriksson MJ, Bos J, Feindel CM, Rakowski H. Dilation of the sinotubular junction causes aortic insufficiency after aortic valve replacement with the Toronto SPV bioprosthesis. J Thorac Cardiovasc Surg. 2001;122:929-34.

\section{Discussion}

Dr Henry M. Spotnitz (New York, NY). There are other issues about valve design that you did not address in your presentation. Can you tell us how the pericardium was preserved if at all, whether you have any information about long-term durability, issues of valvular regurgitation, and how critical you consider the fixation of those tags to the aortic wall? Is that a critical issue, or can they be sewn anyplace? Does it affect the amount of regurgitation? What else can you tell us about that? 